\title{
RoboComm Editorial
}

\author{
Luca Schenato • Francesco De Pellegrini • Jason Redi • \\ Magnus Egerstedt $\cdot$ Alan F. T. Winfield
}

Published online: 27 June 2009

(C) Springer Science + Business Media, LLC 2009

\section{Erratum to: Mobile Netw Appl (2009) 14:265-266 \\ DOI 10.1007/s11036-009-0154-9}

The original version of this article unfortunately contained a mistake. Luca Schenato, Francesco De Pellegrini, Magnus Egerstedt, and Alan FT Winfield were not listed among the authors.

The online version of the original article can be found at http://dx.doi. org/10.1007/s11036-009-0154-9

L. Schenato $(\bowtie)$

University of Padova,

Padova, Italy

e-mail: schenato@dei.unipd.it

F. De Pellegrini $(\bowtie)$

CREATE-NET,

Trento, Italy

e-mail: francesco.depellegrini@create-net.org

J. Redi $(\triangle)$

BBN Technologies,

Cambridge, MA, USA

e-mail: redi@bbn.com

M. Egerstedt $(\square)$

School of Electrical and Computer Engineering,

Georgia Institute of Technology,

Atlanta, GA, USA

e-mail:magnus@ece.gatech.edu

\section{A. F. T. Winfield ( $₫)$}

University of the West of England, Bristol, UK

e-mail: Alan.Winfield@uwe.ac.uk 